\title{
Application of discriminant analysis to parameters describing the drape for two types of woven fabrics
}

\author{
X.Capdevila ${ }^{a}$, E.Carrera-Gallissàa \\ ${ }^{a}$ Departamento de Ingeniería Textil y Papelera, Universitat Politècnica de Catalunya, \\ Spain
}

*Corresponding autor: email: carrera @catunesco.upc.edu

A total of 33 commercial drapery and lining fabrics were used to determine the drape indicators drape ratio $(\% D R)$ and $R$-factor. The slope of a plot of one indicator against the other was found not to afford complete characterization of drape shape for fabrics of different commercial use.

In this work, a further 6 parameters describing the drape, proposed by the authors to discriminate drape shapes were also calculated. Discriminant analysis of the data revealed that a linear combination of various parameters allowed two types of woven fabrics (viz., drapery and linen) to be distinguished.

The discriminant function used accurately classified $75.76 \%$ of the fabrics studied.

Key words: Drape, Discriminant analysis, R-factor

\section{Introduction and objectives}

Drape, together with colour, brightness and texture, is among the most aesthetically significant properties of fabrics; also, it can dictate fabric purchasing criteria. Pierce's (1930) was the first researcher to examine fabric drape and its relationship to bending rigidity. However, fabric drape proper was not measured until 1950, when the first drape meter was developed by Chu et al. (1950). This prototype was subsequently improved by Cusick $(1961,1962,1968)$ and soon became the tool of choice for assessing drape for most standardization agencies. Fabric drape is usually measured in terms of the drape ratio $(\% D R)$, which is the percent ratio of the area of the shadow cast by a circular specimen to that of the undropped specimen (Cusick, 1961). This parameter is calculated from

$$
\% D R=\left(\frac{A-B}{C-B}\right) \times 100
$$

The parameters in which are shown in Fig. 1.

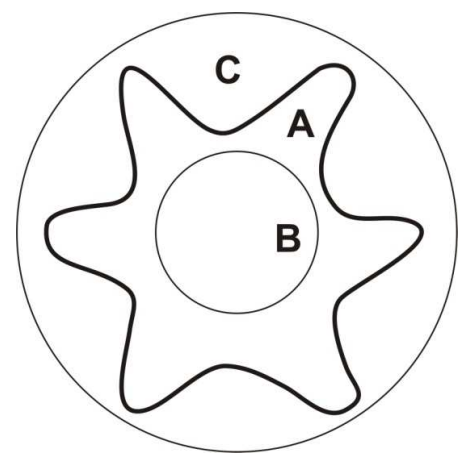

Figure 1. Area of the simple fall. $\mathrm{A}=$ area of the simple fall, $\mathrm{B}=$ base blade area, $\mathrm{C}=$ specimen area 
Drape ratio was followed by another 35 parameters for drape geometry (particularly drape shape) that were proposed until 2013 to overcome its limitations (Carrera, 2014). Specially prominent among such parameters is the $R$-factor, which was developed by Mizutani et al. (2005) to assess the simplicity of drape shape. The $R$-factor is defined mathematically as

$$
\text { Rfactor }=\frac{\sqrt[2]{(r l-e c r)^{2}}}{e c r-R}
$$

where $\overline{(r l-e c r)^{2}}$ is the average value of $(r i-e c r)^{2}$ along the contour of the drape profile, $r_{i}$ denotes the radial coordinates of the drape projection, ecr is the equivalent circle radius (i.e., the radius of a circle of the same area as the drape shadow) and $R$ is the specimen radius. The higher is the $R$-factor, the less simple will be the drape shape of a fabric and the greater the roughness of its drape profile. This parameter seemingly allows one to discriminate drape shape between fabrics with an identical drape ratio $(\% D R)$. Thus, a regression graph relating the $R$-factor with $\% D R$ in 4 specimens each of 3 woven fabrics of different composition (cotton, wool and silk) exhibited differences in slope between fabrics. This suggests that the $R$-factor may provide an effective means for distinguishing fabric types in terms of drape patterns.

The primary aim of this work was to assess the usefulness of the R-factor for discriminating drape shape patterns in drapery and linen fabrics.

Alternatively, to develop drape indicators with an increased discriminating ability for these types of fabrics.

\section{Material}

The study was conducted on 33 woven fabrics for two different commercial purposes, namely: drapery (19 fabrics) and lining (14 fabrics). The structural characteristics of the fabrics are summarized in Table 1.

Table 1. Characteristics of the fabrics studied

\begin{tabular}{|c|c|c|c|c|}
\hline $\begin{array}{l}\text { Specimen } \\
\text { number }\end{array}$ & $\begin{array}{l}\text { Commercial } \\
\text { use }\end{array}$ & Composition & Weave type & $\begin{array}{c}\text { Mass per } \\
\text { square } \\
\text { meter } \\
\left(\mathrm{g} / \mathrm{m}^{2}\right)\end{array}$ \\
\hline 1 & Drapery & WO/PAN 60/40 & Double cloth & 447.41 \\
\hline 2 & Drapery & PES/CV/EA 64/31/5 & Double cloth & 371.45 \\
\hline 3 & Drapery & PES/CV/EAS 78/18/4 & Serge & 341.33 \\
\hline 4 & Drapery & WO/PA 90/10 & Double cloth & 333.26 \\
\hline 5 & Drapery & CO/WO/PA 76/19/5 & Two-sided cloth & 309.14 \\
\hline 6 & Drapery & WO $100 \%$ & Satin & 299.41 \\
\hline 7 & Drapery & $\mathrm{PES} / \mathrm{CV} / \mathrm{EA} 78 / 17 / 5$ & Serge & 279.08 \\
\hline 8 & Drapery & CO $100 \%$ & Mat & 241.16 \\
\hline 9 & Drapery & WO/EA 99/1 & Crepe & 232.16 \\
\hline 10 & Drapery & $\mathrm{PES} / \mathrm{CV} / \mathrm{EA} 65 / 31 / 4$ & Taffeta & 221.17 \\
\hline 11 & Drapery & CO $100 \%$ & Serge-Herring bone & 214.00 \\
\hline 12 & Drapery & WO $100 \%$ & Serge & 209.00 \\
\hline 13 & Drapery & WO/PES 60/40 & Serge-Herring bone & 199.08 \\
\hline 14 & Drapery & WO $100 \%$ & Serge & 191.08 \\
\hline 15 & Drapery & LI $100 \%$ & Taffeta & 186.90 \\
\hline 16 & Drapery & CV/WO/PES 43/34/23 & Taffeta & 171.25 \\
\hline
\end{tabular}




\begin{tabular}{|l|l|l|l|l|}
\hline 17 & Drapery & PES/LI 65/45 & Serge & 163.58 \\
\hline 18 & Drapery & WO/LI/CO/PA 36/32/16/16 & Serge & 157.71 \\
\hline 19 & Drapery & CO/PES 65/35 & Serge & 135.17 \\
\hline 20 & Lining & PES 100\% & Satin & 90.00 \\
\hline 21 & Lining & PES/CV 50/50 & Satin & 90.00 \\
\hline 22 & Lining & CV/CA 55/45 & Serge & 80.00 \\
\hline 23 & Lining & PES 100\% & Satin & 78.40 \\
\hline 24 & Lining & CV/PES 50/50 & Jacquard & 77.50 \\
\hline 25 & Lining & PES 100\% & Serge & 76.50 \\
\hline 26 & Lining & CV 100\% & Serge & 72.00 \\
\hline 27 & Lining & CV 100\% & Taffeta & 70.00 \\
\hline 28 & Lining & CV/PES 60/40 & Serge & 70.00 \\
\hline 29 & Lining & CV/PES 60/40 & Serge & 68.50 \\
\hline 30 & Lining & CA 100\% & Taffeta & 68.00 \\
\hline 31 & Lining & PES/CV 60/40 & Taffeta & 65.00 \\
\hline 32 & Lining & PES/CV 60/40 & Taffeta & 65.00 \\
\hline 33 & Lining & PES 100\% & Taffeta & 50.00 \\
\hline
\end{tabular}

\section{Hardware and methods}

Drape parameters were determined by using a Cusick drape meter equipped with a CCD digital camera. The meter used (Fig. 2) is operated in the Textile Physics Laboratory of the Department of Textile and Paper Engineering of the Polytechnical University of Catalonia (UPC) (Carrera, 2014).

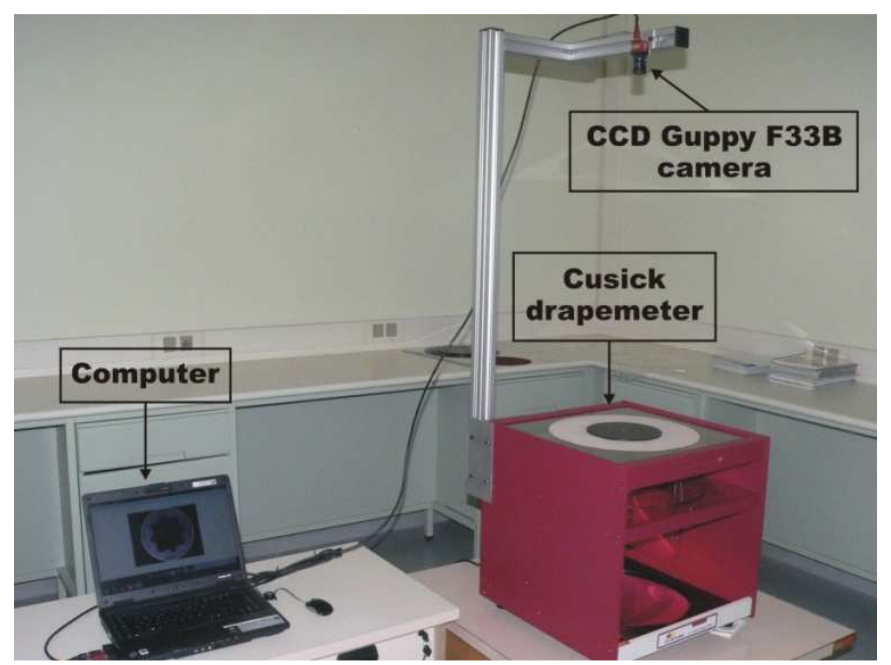

Figure 2. Digital drape meter at the Textile Physics Laboratory of the Department of Textile and Paper Engineering of the Polytechnical University of Catalonia (UPC)

Each type of fabric was used to prepare 4 circular specimens $30 \mathrm{~cm}$ in diameter that were held on a support disc $18 \mathrm{~cm}$ in diameter. Each specimen was measured at three different rotation angles $\left(0,90\right.$ and $\left.135^{\circ}\right)$ in order to ensure that the result would not be affected by its position. Also, each measurement was made on the face and reverse side. Therefore, each value was the arithmetic mean of 24 determinations. The 
average radius, $R_{\text {avg }}$, was the arithmetic mean of 720 readings at $0.5^{\circ}$ intervals of the distance from the centre of the specimen to the edge of the dropped specimen on each side, the result being the average of 24 arithmetic means. All tests were conducted following conditioning of the specimens in a standard atmosphere.

The \%DR values obtained by following Cusick's traditional procedure (viz., cutting and weighing of a piece of paper containing the drape shadow) and the values provided by the UPC digital drape meter, which were used to calculate drape area in terms of a pixel number, were correlated with a Pearson's coefficient of 0.997 and $p=0.000$.

\section{$\boldsymbol{R}$-factor versus \%DR}

The usefulness of the slope of an $R$-factor vs \%DR plot for discriminating drape patterns in woven fabrics of different composition was assessed by using measurements of the 33 fabrics listed in Table 1. Figure 3 illustrates the linear relationship between the $R$-factor and \%DR for the different drapery and lining fabrics. As can be seen, the plot consisted of two straight lines of different slope and intercept.

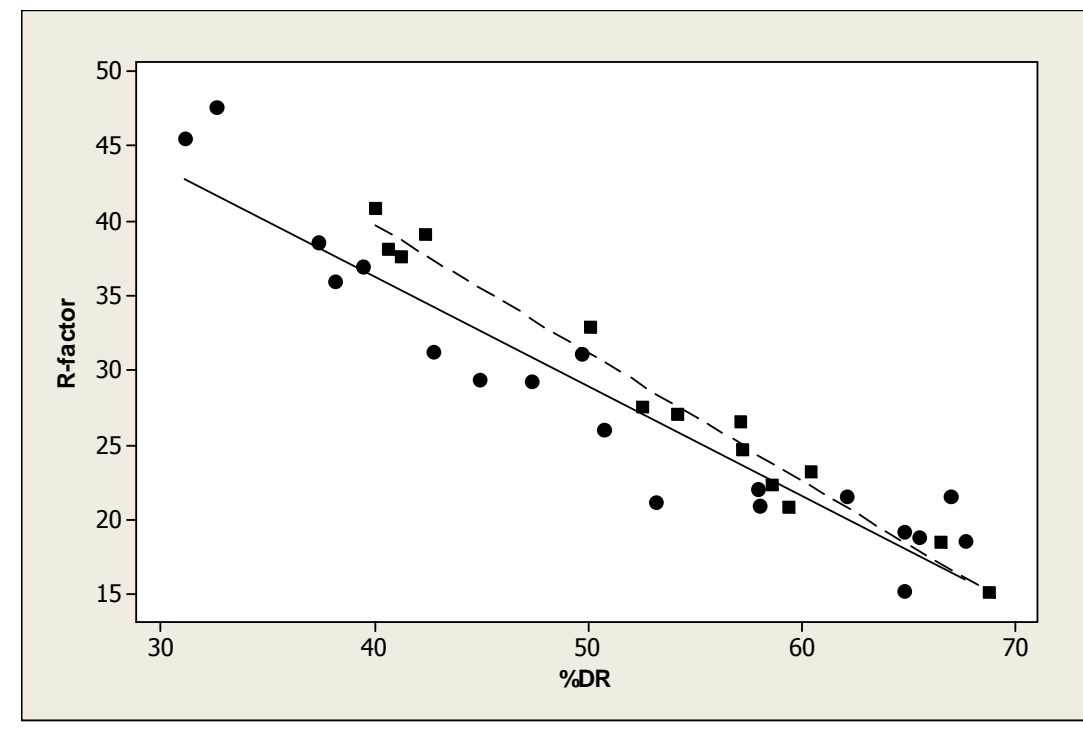

Figure 3. Relationship between R-factor and \%DR:

- -linning

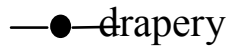

This information was used to develop a single regression equation (see Table 2):

$$
y=\beta_{0}+\beta_{1} x_{1}+\beta_{2} x_{2}+\beta_{3} x_{1} x_{2}+\varepsilon
$$

where $x_{1}$ is the regression variable $\% D R$ and $x_{2}$ the variable denoting fabric type (0 for drapery fabrics and 1 for lining fabrics). Coefficient $\beta_{2}$ reflects the slope change associated with a change in fabric type (from drapery fabrics to lining fabrics). Since the $p$-value relative to $\beta_{3}$ was greater than the significance level of 0.05 -or even 0.10 - the two slopes can be assumed to be identical. Consequently, the slope of a plot of $R$-factor against \%DR does not allow one to distinguish fabrics of different commercial use and composition in terms of drape shape. 
Table 2. Statistical figures of merit of the regression model for the indicator $R$-factor

\begin{tabular}{|c|c|c|c|c|c|}
\hline $\begin{array}{c}\text { Variation } \\
\text { source }\end{array}$ & $\begin{array}{c}\text { Sum of } \\
\text { squares }\end{array}$ & $\begin{array}{c}\text { Degrees of } \\
\text { freedom }\end{array}$ & $\begin{array}{c}\text { Mean } \\
\text { square }\end{array}$ & $\boldsymbol{F}_{\mathbf{0}}$ & $\boldsymbol{p}$-value \\
\hline Model & $2,305.640$ & 3 & 768.55 & 120.84 & 0.000 \\
\hline Error & 184.450 & 29 & 6.35 & & \\
\hline Total & $2,490.090$ & 32 & & & \\
\hline $\begin{array}{c}\text { Regression } \\
\text { coefficient }\end{array}$ & Estimate & Standard error & $\boldsymbol{t}_{0}$ & p-value & \\
\hline$\beta_{0}$ & 65.567 & 2.562 & 25.590 & $0.000^{*}$ & \\
\hline$\beta_{1}$ & -0.733 & 0.048 & -15.070 & $0.000^{*}$ & \\
\hline$\beta_{2}$ & 8.425 & 4.747 & 1.770 & $0.086^{* *}$ & \\
\hline$\beta_{3}$ & -0.123 & 0.088 & -1.400 & 0.179 & \\
\hline${ }^{*} p<0.05$ & ${ }^{* *} p<0.10$ & & & & \\
\end{tabular}

\section{Discriminant analysis}

Technically, discriminant analysis of two groups involves constructing a linear combination of the $p$ input variables best discriminating between the groups. The resulting Fisher's discriminant function takes the form

$$
D=u_{1} x_{1}+u_{2} x_{2}+\ldots+u_{p} x_{p}
$$

The discriminant function is constructed from the greatest eigenvalue of the matrix $\mathrm{W}^{-1} \mathrm{~F}$, where $\mathrm{W}$ and $\mathrm{B}$ are the in-group and between-group sum of squares, respectively. The coefficients $u_{j}$ are the vectors associated to the eigenvalues of the discriminant function, each eigenvalue being a measure of the proportion of variance explained by the function.

\section{Preliminary analysis of data}

In previous work, Carrera (2014) assessed the usefulness of each of the 36 drape parameters describing the drape studied here by using a Cusick digital drape meter on a sample of 37 commercial drapery, woolmaking, shirtmaking and lining fabrics spanning a wide range of composition, weave and aerial weight. Correlation analysis revealed that 7 of the indicators were more useful than the other 29 for the intended purpose. Also, principal component analysis exposed the presence of 3 common factors accounting for (1) drape intensity, (2) severity, and (3) shape symmetry and variability. The results were subjected to cluster analysis for easier, graphical viewing. Finally, a procedure based on sequential application of 4 selected parameters was developed and experimentally validated to distinguish drape shape in fabrics with an identical drape ratio $(\% D R)$.

In this work, the seven parameters previously selected by Carrera (2014) were used to develop a synthetic parameter for fabric category in the form of a discriminant function. The parameters used for this purpose are as follows:

(a) Drape ratio, \%DR (Cusick, 1968), eq (1). 
(b) Fold Number, FN (Chu et al. 1960). A fold is defined here as the maximum of the projection of the drape profile on a plane. Geometrically, folds are roughly triangles of width FW and height $\mathrm{FH}$ having a peak (FP) and two adjacent valleys (FV) as vertices (see Fig. 4).

(c) Mean fold height, FH (May-Plumle et al., 2003), which measured in $\mathrm{mm}$ from the line used to measure FW (see Fig. 4).

$$
F H=\sum_{i=1}^{n} \frac{F H i}{n}
$$

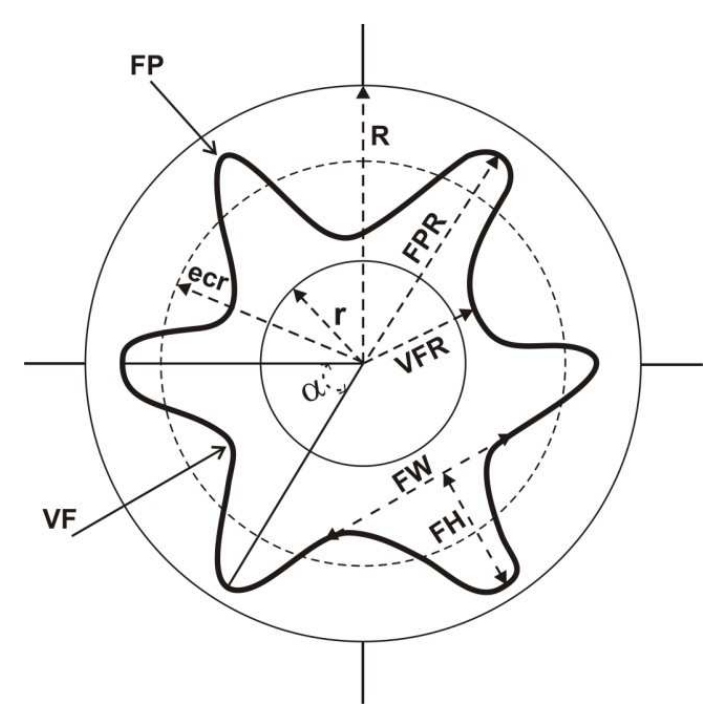

Figure $4 . \mathrm{FP}=$ fold peak, $\mathrm{VF}=$ valley fold, $\mathrm{FPR}=$ fold peak radius, VFR $=$ valley fold radius, $\mathrm{FW}=$ fold width, $\mathrm{FH}=$ fold height, $r=$ support disc radius, $R=$ specimen radius, ecr $=$ equivalent circle radius, $\alpha=$ angle between consecutive folds

(d) Variability of node severity, VS (Robson \& Long, 2000). VS represents the standard deviation of node severity in a given specimen and is a measure of unevenness in fold shape and severity. This parameter accounts for fold evenness in a specimen, but not for fold shape (see Fig. 5).

$$
V S=\sqrt{\frac{\sum_{i=1}^{n}(M N S i-\overline{\mathrm{MNS}})^{2}}{n-1}}
$$




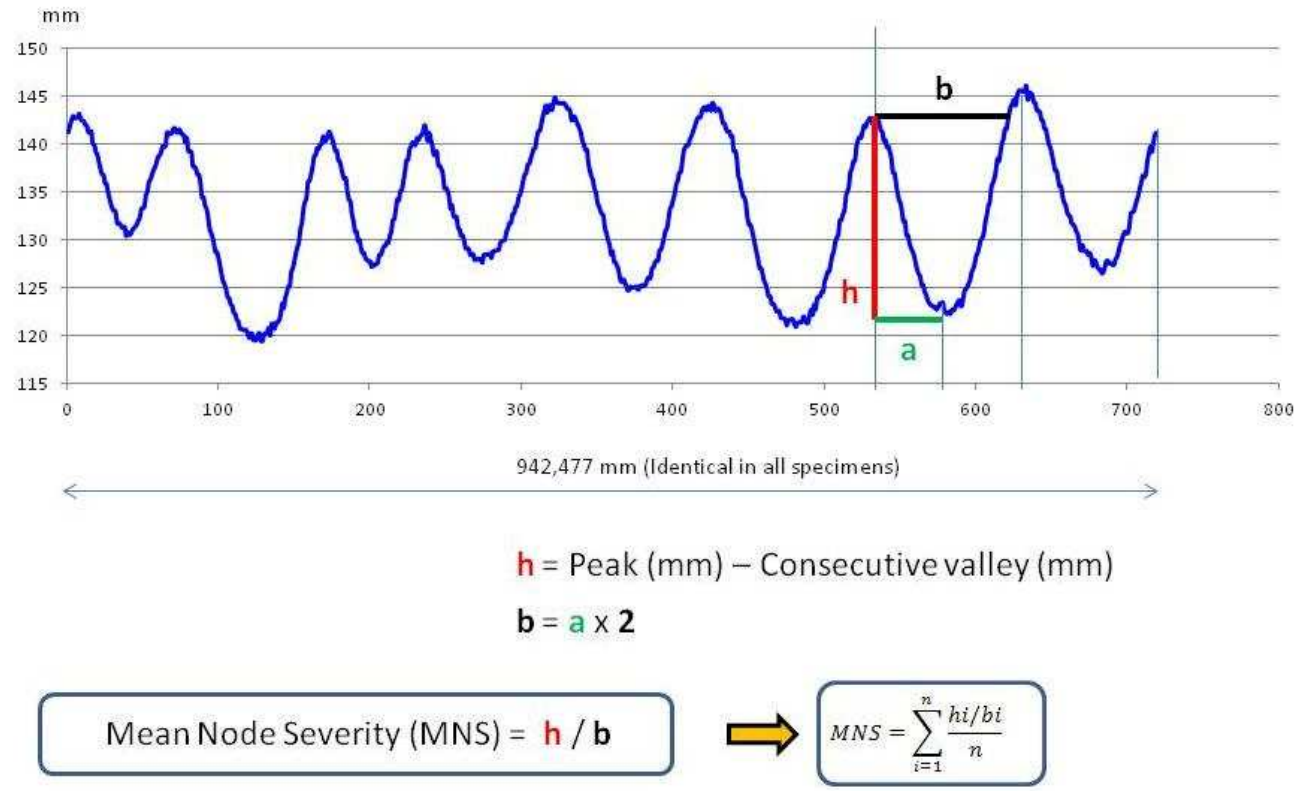

Figure 5. Mean node severity

(e) Drape unevenness, \%DU (Al-Gaadi, Göktepe \& Halász, 2012). This is the coefficient of variation between consecutive folds and accounts for drape symmetry in each specimen, but not for drape shape. This parameter is expressed as a percentage and can range from $0 \%$ (maximum symmetry) to $100 \%$ (minimum symmetry).

$$
D U \%=\frac{\sqrt{\frac{\sum_{i=1}^{n}(\alpha \mathbf{i}-\bar{\alpha})^{2}}{n-1}}}{\bar{\alpha}} \times 100
$$

(f) Fold distribution, \%Gp (Jevsnik \& Gersak, 2004). \%Gp represents the percent coefficient of variation of peak length (FPR, Fig. 4) and is a measure of variability in fold shape and symmetry in each specimen.

$$
G p \%=\frac{\sqrt{\frac{\sum_{i=1}^{n}(F P R \mathrm{i}-\overline{F P R})^{2}}{n-1}}}{\overline{F P R}} \times 100
$$

(g) Fitness factor, D/O (Park, Kim \& Yu, 2004). This parameter is calculated as the ratio of the areas bound by the curve of the dominant wave in the Fourier transform to that of the original shadow cast by a specimen. If the ratio is nearunity, the original curve is very similar to the curve for the dominant wave, which is a perfect sine function; as a consequence, the original curve will result in a highly even, symmetric drape with very similar shapes (i.e., a high periodicity and evenness). In fact, D/O accounts for shape evenness and symmetry -and hence for geometric isotropy. Thus, the more D/O departs from 1, the less isotropic -or more anisotropic - will be drape shape. This parameter can range from 0 (minimum geometric isotropy) to 1 (maximum isotropy).

The previous seven parameters were used for hypothesis testing by comparing means for the two groups of fabrics. Table 3 shows the statistics for the parameters and the corresponding significance levels ( $p$-values). The asterisks denote actual differences (i.e., significance at the $95 \%$ confidence level) in FN and \%Gp between the two fabric groups. 
Table 3. Results of the mean difference test

\begin{tabular}{|c|c|c|c|c|c|c|}
\hline $\begin{array}{c}\text { Fabric } \\
\text { type }\end{array}$ & \multicolumn{2}{|c|}{ Drapery } & \multicolumn{2}{|c|}{ Lining } & \multirow{3}{*}{$\begin{array}{c}\text { Student's } \\
t\end{array}$} & \multirow{3}{*}{$p$-value } \\
\hline Number of & \multicolumn{2}{|c|}{19} & \multicolumn{2}{|c|}{14} & & \\
\hline & Mean & Std dev. & Mean & Std. Dev. & & \\
\hline$\% D R$ & 51.273 & 12.213 & 53.502 & 9.499 & -0.490 & 0.560 \\
\hline$F N$ & 8.448 & 1.095 & 7.773 & 0.428 & 2.440 & $0.022^{*}$ \\
\hline $\mathrm{FH}$ & 32.272 & 3.008 & 33.914 & 3.179 & -1.500 & 0.145 \\
\hline$\% D U$ & 18.471 & 3.748 & 18.280 & 4.713 & 0.130 & 0.901 \\
\hline$\% G p$ & 1.972 & 0.368 & 2.382 & 0.586 & -2.300 & $0.032^{\star}$ \\
\hline$\% V S$ & 0.068 & 0.033 & 0.082 & 0.020 & -1.530 & 0.138 \\
\hline$D / O$ & 0.974 & 0.007 & 0.975 & 0.004 & -0.380 & 0.706 \\
\hline
\end{tabular}

${ }^{*} p<0.05$

Based on the results of Table 3, the parameters FN and \%Gp are worth using in discriminant analysis of fabrics. Also, they meet the essential criteria for this purpose, namely: a minimum size of five observations per independent variable, a normal distribution (see Figs 6 and 7 ) and no multicollinearity (correlation coefficient $=0.1604$ ).

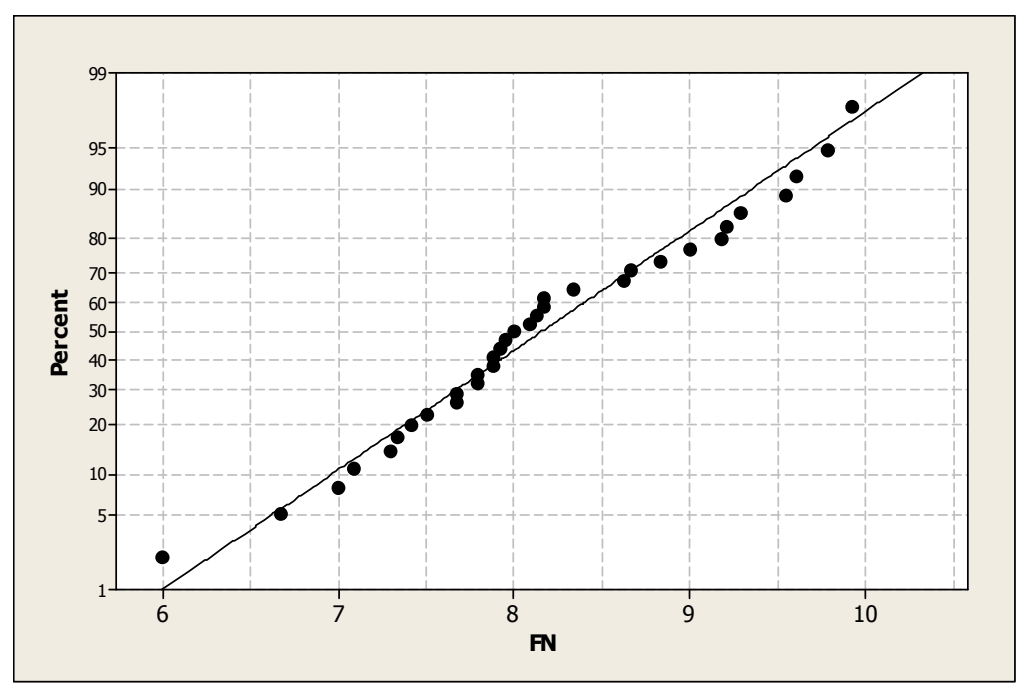

Figure 6. Probability plot of FN 


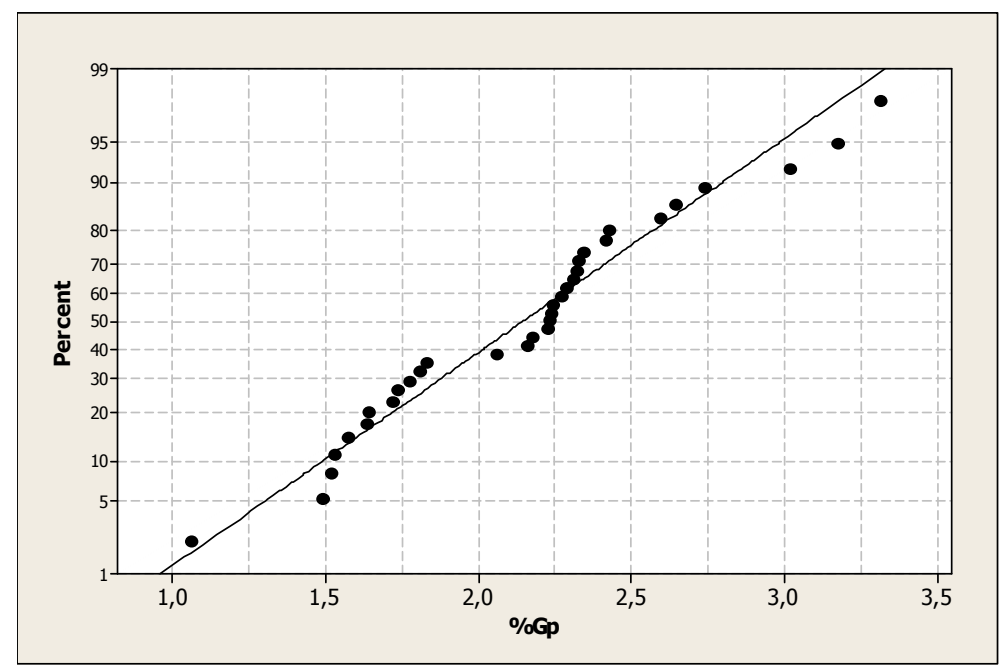

Figure 7. Probability plot of \%Gp

\section{Discriminant function}

Using the previous two parameters allowed the 33 fabrics studied to be represented by a point in a two-dimensional space that was converted into a one-dimensional space the axis of which coincided with the discriminant function. As a result, the projection of the point cloud led to the points for each group falling close to one another but those for fabrics of one group falling apart from those of the other.

Table 4 testifies to the significance of the resulting discriminant function. The percent variance measures the relative discriminating power of discriminant functions; such a percent was 100 here as only one function was used. The canonical correlation coefficient, $\eta$, and Wilks' $\Lambda$, which can range from 0 to 1 , measure the difference between the means of the functions for the groups; thus, a high $\eta$ value indicates a close relationship between a fabric group and the values of the discriminant function, whereas a near-unity $\wedge$ value is suggestive of little discrimination or difference between groups and a near-zero value if suggestive of the opposite (i.e., of marked separation between groups). However, it is desirable to support this interpretation of $\Lambda$ with a statistical test allowing one to assess the significance of this parameter. In this work, we used Barlett's $V$, which has a known, tabulated asymptotic distribution of chisquared -and the $p$-value less than 0.05 for 10.4331 is statistically significant with a confidence level of $95 \%$.

Table 4. Statistical figures of merit of the discriminant function

\begin{tabular}{|c|c|c|c|c|c|c|c|}
\hline Function & Eigenvalue & $\%$ Variance & $\begin{array}{c}\text { Canonical } \\
\text { correlation }\end{array}$ & $\begin{array}{c}\text { Wilks' } \\
\Lambda\end{array}$ & $\mathbf{X}^{2}$ & $\begin{array}{c}\text { Deg. } \\
\text { freedom }\end{array}$ & $\begin{array}{c}\boldsymbol{p} \text { - } \\
\text { value }\end{array}$ \\
\hline 1 & 0.415 & 100 & 0.541 & 0.706 & 10.433 & 2 & 0.005 \\
\hline
\end{tabular}

The standardized discriminant function was

$$
D=-0.7361 F N+0.8051 G p
$$

and the non-standardized version 


$$
D=3.16794-0.8365 F N+1.705 G p
$$

The relative magnitude of the coefficients of eq. 9 allows one to assess the contribution of each indicator to discrimination between groups. As can be seen, \%Gp was a slightly greater contributor than FN. This was also the case judging by the linear correlation coefficient between each indicator (explanatory variable) and the discriminant function (the so-called "structural correlation coefficient") (see Table 5).

Table 5. Structural correlation coefficient

\begin{tabular}{|c|c|c|c|c|}
\hline & \multicolumn{2}{|c|}{ FN } & \multicolumn{2}{c|}{ \%Gp } \\
\cline { 2 - 5 } & Correlation & $p$-value & Correlation & $p$-value \\
\hline $\boldsymbol{D}$ & -0.679 & 0.000 & 0.741 & 0.000 \\
\hline
\end{tabular}

\section{Validation of the discriminant function}

One intuitive measure of the ability of a function to discriminate between groups is provided by the hit ratio, which is defined as the proportion of elements (fabrics here) accurately classified according to a given criterion. Table 6 shows the classification matrix used to determine the number of elements accurately (main diagonal) and inaccurately classified. The hit ratio was $75.76 \%$.

Table 6. Classification matrix

\begin{tabular}{|c|c|c|c|}
\hline Actual group & \multirow{2}{*}{ Group size } & \multicolumn{2}{|c|}{ Predicted group } \\
\cline { 3 - 4 } & & Lining & Drapery \\
\hline Drapery & 14 & 11 & 3 \\
\hline & & $(78.57 \%)$ & $(21.43 \%)$ \\
\hline Lining & 19 & 5 & 14 \\
\hline & & $(26.32 \%)$ & $(73.68 \%)$ \\
\hline
\end{tabular}

A more objective alternative is provided by the jack-knife method, which establishes the discriminant function by using a leave-one-out procedure. As can be seen from the selected results shown in Table 7, the 33 functions obtained were quite stable and had very similar coefficients.

Table 7. Standardized coefficients of the discriminant functions as obtained with the jack-knife method

\begin{tabular}{|c|c|c|c|}
\hline $\begin{array}{c}\text { Specimens } \\
\text { removed }\end{array}$ & $\begin{array}{c}\text { Coefficient of } \\
\text { FN }\end{array}$ & $\begin{array}{c}\text { Coefficient of } \\
\text { \%Gp }\end{array}$ & $\begin{array}{c}\text { Hit ratio } \\
\text { (\%) }\end{array}$ \\
\hline 2 & -0.736 & 0.809 & 75.00 \\
\hline 8 & -0.736 & 0.805 & 75.76 \\
\hline 13 & -0.716 & 0.819 & 75.00 \\
\hline 25 & -0.759 & 0.777 & 75.00 \\
\hline 27 & -0.690 & 0.855 & 78.13 \\
\hline
\end{tabular}


A discriminant function is appropriate when it accurately classifies at least $25 \%$ of the hits obtained by random classification. Under the criterion of proportional likelihood, such a level should be $51.14 \%$, which is clearly exceeded by our function: $75.76 \%$ > $[51.14+(0.25 \times 51.14)=63.93 \%]$

\section{Conclusions}

As found in this work, the slope of a plot of $R$-factor versus drape ratio does not allow drape shape for fabrics of different composition and commercial use to be distinguished. However, a linear combination of selected drape parameters allows two different types of fabrics (drapery and lining) to be easily distinguished in this respect. Application of the multivariate technique discriminant analysis revealed the following:

(a) The parameters FN and \%Gp differ significantly between drapery and lining fabrics.

(b) Using a linear function of the previous two parameters -a discriminant functionallows drapery and lining fabrics to be distinguished.

(c) $\% G p$ is a greater contributor to discrimination between the two types of fabrics than is $\mathrm{FN}$.

(d) The proposed discriminant function accurately classified $75.76 \%$ of all fabrics studied.

Whereas discriminating fabrics in terms of drape shape requires using seven parameters (viz., \%DR, FN, FH, \%DU, \%Gp, VS and D/O) (Carrera, 2014), distinguishing drapery fabrics from lining fabrics only requires a linear combination of two: FN and \%Gp.

In summary, this paper predicts the typology of drapery and lining fabrics from the study of drapeability

\section{References}

Al-Gaadi, B. Göktepe, F. \& Halász, M. (2012). A new method in fabric drape measurement and analysis of the drape formation process. Textile Research Journal, $82,502-512$.

Carrera, E. (2014). Nuevas perspectivas sobre la evaluación del cayente de los tejidos de calada. PhD Thesis. Universitat Politècnica de Catalunya.

Chu, C. C.; Cummings, C. L. \& Teixeira, N. A. (1950). Mechanics of elastic performance of textile materials. Part V: A study of the factors affecting the drape of fabrics. The development of a drape meter. Textile Research Journal, 20, 539-548.

Cusick, G. E. (1961). The resistance of fabrics to shearing forces. Journal of the Textile Institute, 52, 395-406.

Cusick, G. E. (1962). A study of fabric drape. University of Manchester.

Cusick, G. E. (1968). The measurement of fabric drape. Journal of the Textile Institute, 59 (6), 253-260.

Jevsnik, S. \& Gersak, J. (2004). Modelling the fused panel for a numeric simulation of drape. Fibres \& Textiles in Eastern Europe, 12, 47-52 
May-Plumlee, T., Eischen, J., Kenkare, N. \& Pandurangan, P. (2003). Evaluating 3D drape simulations: Methods and metrics. In: Proceedings of the International Textile Design and Engineering Conference (INTEDEC), Edinburgh, Scotland.

Mizutani, C., Amano, T. \& Sakaguchi, Y. (2005). A new apparatus for the study of fabric drape. Textile Research Journal, 75 (1), 81-87.

Robson, D. \& Long, C. C. (2000). Drape analysis using image techniques. Clothing and Textiles Research Journal, 18, 1-8.

Park, C.K., Kim, S. \& Yu, W.R. (2004). Quantitative fabric drape evaluation system using image processing technology (Part 1: Measurement system and geometric model). Journal of Testing Evaluation, 32, 131-137.

Pierce, F.T. (1930). The handle of cloth as a measurable quantity. Journal of the Textile Institute, 21, 377-419. 